\title{
Current Mode Programmable Analog Modules using Low voltage Digitally Controlled CMOS CCII
}

\author{
lqbal A. Khan \\ Department of Electrical Engineering, \\ Faculty of Engineering and Islamic Architecture, \\ Umm Al Qura University, Makkah, Saudi Arabia
}

\author{
Ahmed M. Nahhas \\ Department of Electrical Engineering, \\ Faculty of Engineering and Islamic Architecture, \\ Umm Al Qura University, Makkah, Saudi Arabia
}

\begin{abstract}
The current mode programmable analog modules are realized using digitally controlled low voltage CMOS current conveyors. These programmable modules include current mode amplifiers, integrators, differentiators, first order multifunctional filter and second order multifunctional filters. The realized current mode programmable analog modules can provide digital control to the parameters through an n-bit control word with high resolution capability and reconfigurability. These programmable analog modules are suitable for realizing current mode field programmable analog array. The realized programmable analog modules are designed and verified using PSPICE and the results thus obtained justify the theory.
\end{abstract}

\section{General Terms}

Digitally programmable analog modules.

\section{Keywords}

Current conveyors, current mode amplifiers, filters.

\section{INTRODUCTION}

Recently, the introduction of digital control to the current conveyor (CCII) has boosted its functional capability and versatility in addition to its higher signal bandwidth, greater linearity and large signal bandwidth [1-14]. This digital control has eased the on chip control of continuous time systems with high resolution capability and reconfigurability [1-8].

This paper basically deals with the realization of reconfigurable current mode programmable analog modules (CMPAMs) using digitally controlled low voltage CMOS CCII [1-4], [6-8]. The realized CMPAMs include the current mode amplifiers, integrators, differentiators, first order and second order multifunctional filters using Low voltage digitally programmable CMOS CCII (DPCCII). All the realized CMPAMs provide digitally programmable module parameters through an n-bit control word. These CMPAMs can be used as a programmable module of a field programmable analog array (FPAA) [15], [16]. To verify the theory, the realized CMPAMs are designed and verified using PSPICE and the results thus obtained justify the theory.

\section{THE CMOS DPCCII}

The digitally programmable CCII (DPCCII) symbol is shown in "Figure 1(a)" and its CMOS implementation with 4-bit control word is shown in "Figure 1(b)" [4], [8]. The current summing network (CSN) is included at port-X. The transfer matrix can be expressed as

$$
\left[\begin{array}{l}
I_{Y} \\
V_{X} \\
I_{Z}
\end{array}\right]=\left[\begin{array}{ccc}
0 & 0 & 0 \\
\alpha & 0 & 0 \\
0 & \pm \beta N^{m} & 0
\end{array}\right]\left[\begin{array}{l}
V_{Y} \\
I_{X} \\
V_{Z}
\end{array}\right]
$$

Thus the port voltages and currents for DPCCII can be expressed as

$$
\begin{aligned}
& I_{Y}=0, \\
& V_{X}=\alpha V_{Y}, \\
& I_{Z}= \pm \beta N^{m} I_{X}
\end{aligned}
$$

In equation (2) $\alpha$ is the voltage transfer gain from terminal-Y to terminal- $X$ and $\beta$ is the current transfer gain from $X$ to $Z$. Both the voltage gain $(\alpha)$ and the current gain $(\beta)$ are ideally unity. $\mathrm{N}$ is an $\mathrm{n}$-bit digital control word, the plus sign(+) is for $I_{Z+}$ and minus sign(-) is for $I_{Z^{-}}$. The power integer $m=1$ for current summing network (CSN) at port- $\mathrm{Z}$ and $\mathrm{m}=-1$ for current summing network (CSN) at port-X of the DPCCII [1], [4-8]. The additional number of Z+ or Z- outputs may be added as per requirement just by connecting in parallel a set of PMOS and NMOS for each output as shown in "Figure 1(b)".

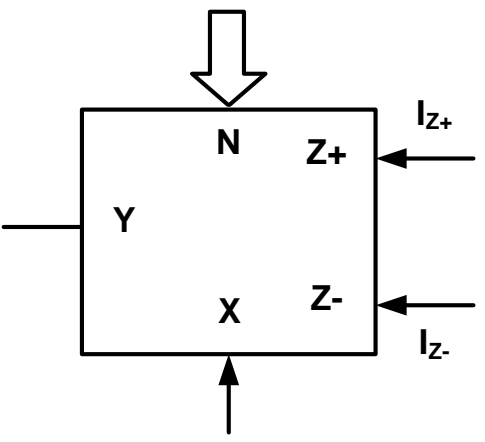

Fig 1(a): Symbol for 4-bit DPCCII 


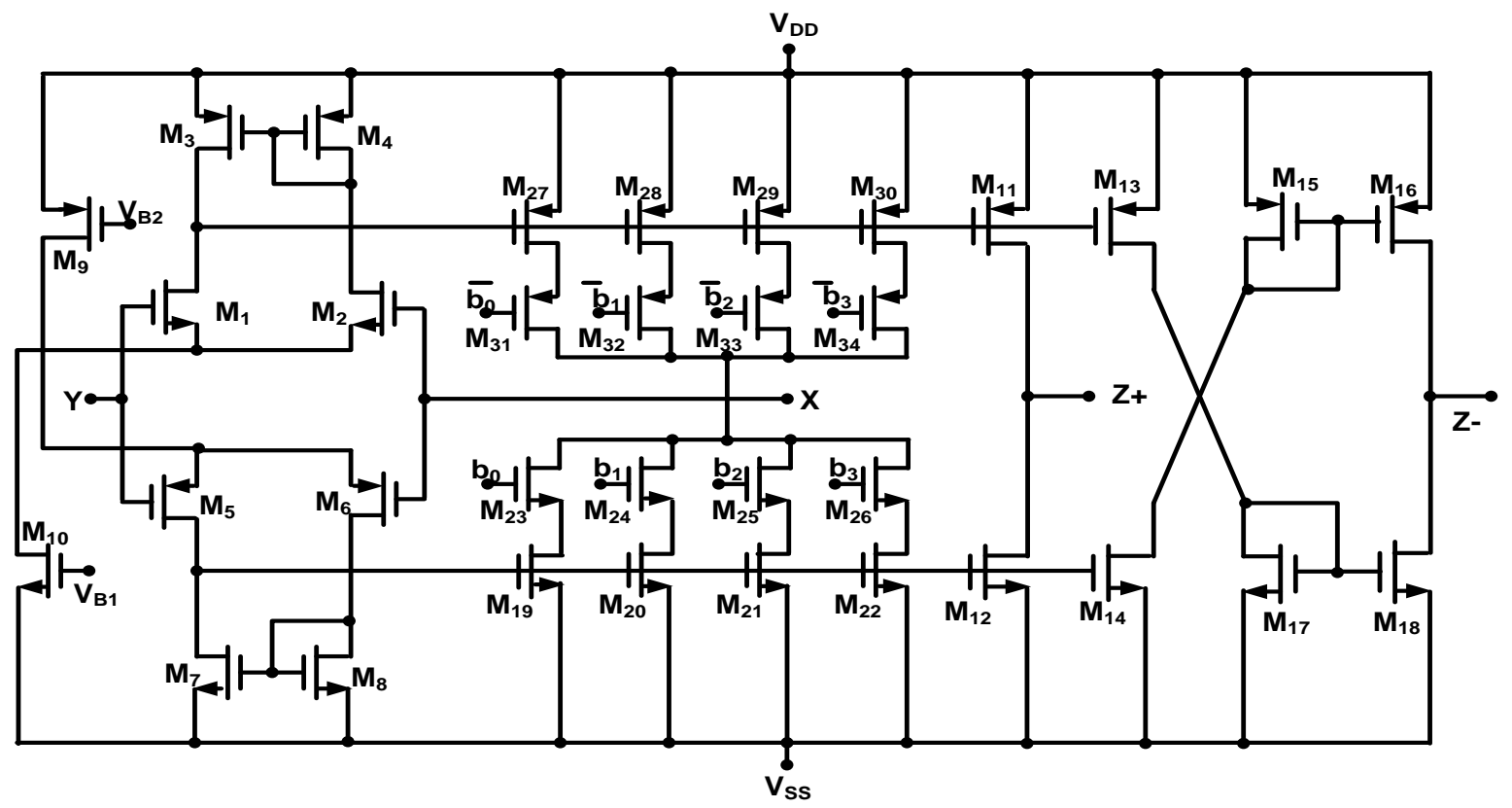

Fig 1(b): The CMOS implementation of a 4-bit DPCCII with CSN at port X

\section{THE CMPAM CIRCUITS}

Three current mode programmable analog module circuits are given, viz., CMPAM-1, CMPAM-2, and CMPAM-3.

\subsection{CMPAM-1: Digitally Progrmmable Current Amplifiers}

The CMPAM-1 is the digitally programmable current amplifier using CMOS DPCCII is shown in "Figure 2". The circuit uses one DPCCII along with grounded resistors $\mathrm{R}_{1}$ and $\mathrm{R}_{2}$.

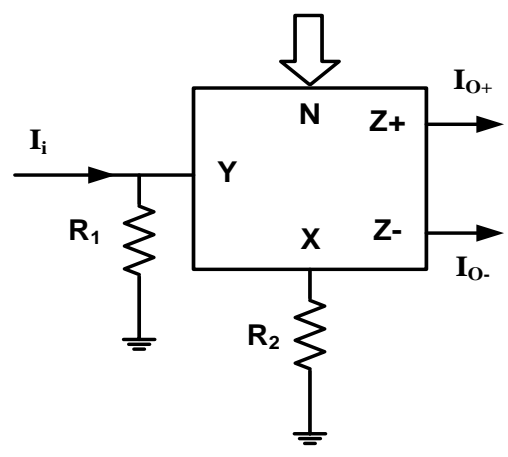

Fig 2: CMPAM-1: Digitally Progrmmable Current Amplifiers

The routine analysis yields its non-inverting and inverting current gains respectively $\mathrm{G}_{+}$and $\mathrm{G}_{-}$as follows.

$$
G_{+}=\frac{I_{O+}}{I i}=\alpha \beta N^{m} \frac{R_{1}}{R_{2}}
$$

and

$$
G_{-}=\frac{I_{O-}}{I i}=-\alpha \beta N^{m} \frac{R_{1}}{R_{2}}
$$

From equation (3) it is clear that the current gains can be set directly or inversely proportional to n-bit digital control word
$\mathrm{N}$ by choosing the DPCCII with $\mathrm{m}=+1$ or -1 , respectively as described in Section-II. It is to be noted that both the resistors can be set equal to minimize the component spread which is desirable for IC implementation. The non-ideal gains $\alpha$ and $\beta$ may slightly affect the gain which can be adjusted through resistors ratio $R_{2} / R_{1}$.

It is also to be noted that by replacing $\mathrm{R}_{1}$ with a capacitor in "Figure 2", the CMPAM-1 results a digitally programmable integrator with inverting and non-inverting outputs. Similarly, by replacing $R_{2}$ with a capacitor the CMPAM-1results a digitally programmable differentiator with inverting and noninverting outputs.

\subsection{CMPAM-2: Digitally Programmable Current Mode First-Order Multifunctional Filters}

The CMPAM-2 is the digitally programmable current mode first order multifunctional filter using CMOS DPCCII is shown in "Figure 3" [7]. The circuit uses one CCII and one DPCCII, each one with three outputs along with grounded R and $\mathrm{C}$ components. The DPCCII uses the CSN at port-X as shown in "Figure 1(b)". The routine analysis yields its current transfer functions respectively for low pass, high pass and all pass filters as

$$
\frac{I_{L P}}{I_{I N}}=\frac{\frac{N}{R C}}{s+\frac{N}{R C}}
$$

$$
\frac{I_{H P}}{I_{I N}}=\frac{s}{s+\frac{N}{R C}}
$$




$$
\frac{I_{A P}}{I_{I N}}=-\frac{s-\frac{N}{R C}}{s+\frac{N}{R C}}
$$

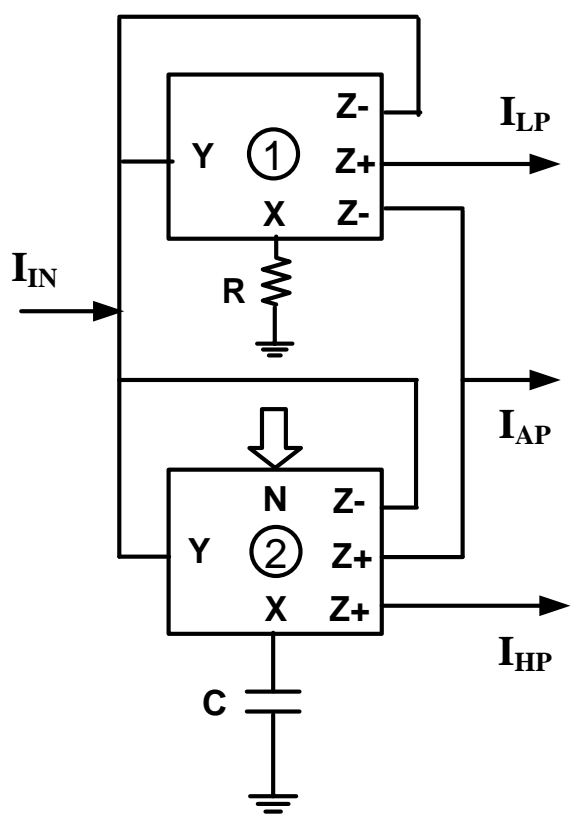

Fig 3: The CMPAM-2: Digitally Programmable Current Mode First order Multifunctional filter

The pole frequency $\left(\omega_{0}\right)$ and the phase angle $(\phi)$ for the APF can be expressed as follows.

$$
\begin{aligned}
& \omega_{0}=\frac{N}{R C} \\
& \Phi=-2 \tan ^{-1}\left(\frac{\omega R C}{N}\right)
\end{aligned}
$$

From equation (4) it is evident that the pole frequency $\omega_{0}$ is directly proportional to the digital control word $\mathrm{N}$. Also the phase can be controlled through $\mathrm{N}$ at any constant pole- $\omega_{0}$. The control through external digital control word N, facilitate the on chip system control. Thus the multifunctional filter of "Figure 2" can be used as a programmable module of a field programmable analog array (FPAA) [15].

Taking the non-idealities of CCIIs into account as given in equation((2), with $\alpha_{1}$ and $\beta_{1}$ for CCII- 1 and $\alpha_{2}$ and $\beta_{2}$ for CCII-2, the ideal transfer functions given in equation (4) yield the non-ideal transfer functions as follows.

$$
\frac{I_{L P}}{I_{I N}}=\frac{\frac{\alpha_{1} \beta_{1} N}{\alpha_{2} \beta_{2} R C}}{s+\frac{\alpha_{1} \beta_{1} N}{\alpha_{2} \beta_{2} R C}}
$$

$$
\begin{gathered}
\frac{I_{H P}}{I_{I N}}=\frac{s}{s+\frac{\alpha_{1} \beta_{1} N}{\alpha_{2} \beta_{2} R C}} \\
\frac{I_{A P}}{I_{I N}}=-\frac{s-\frac{\alpha_{1} \beta_{1} N}{\alpha_{2} \beta_{2} R C}}{s+\frac{\alpha_{1} \beta_{1} N}{\alpha_{2} \beta_{2} R C}}
\end{gathered}
$$

Also the equation (5) reduces to

$$
\begin{aligned}
& \omega_{0}=\frac{\alpha_{1} \beta_{1} N}{\alpha_{2} \beta_{2} R C} \\
& \Phi=-2 \tan ^{-1}\left(\frac{\omega \alpha_{2} \beta_{2} R C}{\alpha_{1} \beta_{1} N}\right)
\end{aligned}
$$

The equations (6) and (7) show that with $\alpha_{1}=\alpha_{2}$ and $\beta_{1}=\beta_{2}$, the pole-frequency for first order multifunctional filter and the phase angle $\phi$ for the all pass section are unaffected due to non-idealities.

\subsection{CMPAM-3: Digitally Programmable Current Mode Second-Order Multifunctional Filters}

The CMPAM-3 is the digitally programmable current mode second order multifunctional filter using low voltage digitally controlled CMOS DPCCII with $\mathrm{m}=1$, is shown in "Figure 4". The circuit uses three DPCCII, each one with two outputs along with grounded $\mathrm{R}$ and $\mathrm{C}$ elements.

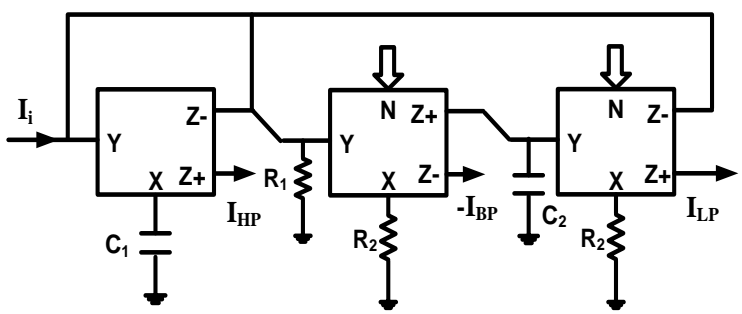

Fig 4: The CMPAM-3: Digitally Programmable Current Mode Second order Multifunctional filter

The routine analysis yields its current transfers functions respectively for low pass filter (LPF), band pass filter (BPF) and high pass filter (HPF) as follows.

$$
\begin{gathered}
\frac{I_{L P}}{I_{I N}}=\frac{\frac{N^{2}}{R_{2} R_{3} C_{1} C_{2}}}{s^{2}+s \frac{1}{R_{1} C_{1}}+\frac{N^{2}}{R_{2} R_{3} C_{1} C_{2}}} \\
\frac{I_{B P}}{I_{I N}}=\frac{-s \frac{N}{R_{2} C_{1}}}{s^{2}+s \frac{1}{R_{1} C_{1}}+\frac{N^{2}}{R_{2} R_{3} C_{1} C_{2}}}
\end{gathered}
$$




$$
\frac{I_{H P}}{I_{I N}}=\frac{s^{2}}{s^{2}+s \frac{1}{R_{1} C_{1}}+\frac{N^{2}}{R_{2} R_{3} C_{1} C_{2}}}
$$

By just directly adding $\mathrm{I}_{\mathrm{HP}}$ and $\mathrm{I}_{\mathrm{LP}}$ the Band Reject (BR) output $\left(\mathrm{I}_{\mathrm{BR}}\right)$ response can easily be obtained and the resulting transfer function can be expressed as follows.

$$
\frac{I_{B R}}{I_{I N}}=\frac{s^{2}+\frac{N^{2}}{R_{2} R_{3} C_{1} C_{2}}}{s^{2}+s \frac{1}{R_{1} C_{1}}+\frac{N^{2}}{R_{2} R_{3} C_{1} C_{2}}}
$$

And by directly adding $\mathrm{I}_{\mathrm{HP}}, \mathrm{I}_{\mathrm{BP}}$ and $\mathrm{I}_{\mathrm{LP}}$ with $\mathrm{R}_{1}=\mathrm{R}_{2}$, the AllPass output $\left(\mathrm{I}_{\mathrm{AP}}\right)$ response can easily be obtained and the resulting transfer function can be expressed as follows.

$$
\frac{I_{A P}}{I_{I N}}=\frac{s^{2}-s \frac{N}{R_{1} C_{1}}+\frac{N^{2}}{R_{2} R_{3} C_{1} C_{2}}}{s^{2}+s \frac{1}{R_{1} C_{1}}+\frac{N^{2}}{R_{2} R_{3} C_{1} C_{2}}}
$$

From equation (4) the filter parameters can be expressed as follows.

The pole frequency

$$
\omega_{0}=\frac{N}{\sqrt{C_{1} C_{2} R_{2} R_{3}}}
$$

The pole-Q

$$
Q=R_{1} N \sqrt{\frac{C_{1}}{C_{2} R_{2} R_{3}}}
$$

If resistance $R_{1}$ is replaced by an equivalent digitally programmable resistor (DPR) as shown in "Figure 5", and

$$
R_{1}=\frac{R}{N_{0}}
$$

with $\mathrm{R}=\mathrm{R}_{2}=\mathrm{R}_{3}$, and $\mathrm{C}_{1}=\mathrm{C}_{2}=\mathrm{C}$, the pole- $\omega_{0}$ and pole- $\mathrm{Q}$ from equation (5) reduces to

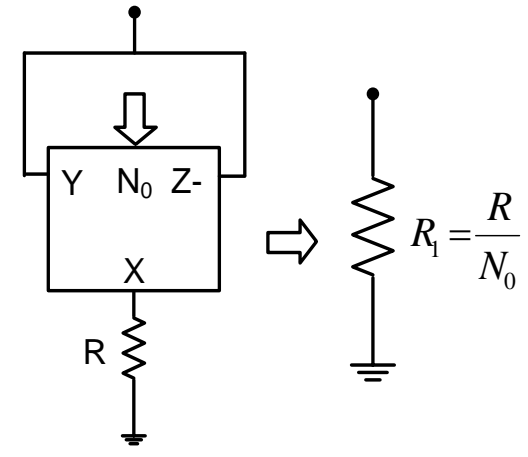

Fig 5: The digitally programmable resistor (DPR) using CMOS DPCCII with $\mathbf{m}=1$

$$
\begin{gathered}
\omega_{0}=\frac{N}{R C} \\
Q=\frac{N}{N_{0}}
\end{gathered}
$$

The filter gains are

$$
\mathrm{H}_{\mathrm{LP}}=\mathrm{H}_{\mathrm{HP}}=1 \text {, and the } \mathrm{H}_{\mathrm{BP}}=\mathrm{Q}
$$

From equation (6) it is evident that the pole frequency $\omega_{0}$ is directly proportional to digital control word N. The pole-Q can be independently controlled through the digital control word $\mathrm{N}_{\mathrm{Q}}$. The minimum $\mathrm{N}_{0}=1$, and thus maximum $\mathrm{Q}=\mathrm{N}$. However, by selecting the DPCCII with $m=-1$, for the DPR of "Figure 5", with $\mathrm{R}_{1}=\mathrm{RN}_{0}$, results the pole-Q as

$$
\mathrm{Q}=\mathrm{NN}_{0}
$$

Thus from equation (7), it is obvious that the pole-Q can be independently and directly controlled through the digital control word $\mathrm{N}_{0}$. Now with $\mathrm{N}_{0}=1$ the minimum $\mathrm{Q}=\mathrm{N}$. The maximum $\mathrm{Q}=\mathrm{NN}_{0}$ and the choice is suited for designing high-Q filter.

Taking the non-idealities of CCIIs into account as given in equation (2), for the CMPAM-2 of "Figure 4", with identical $\alpha$ and $\beta$ for all the CCIIs, the ideal relationship of pole- $\omega_{0}$, filter gains and pole-Q given in equation(11) and (12) respectively, yields the non-ideal pole- $\omega_{0}$, filter gains and pole-Q as follows.

$$
\begin{gathered}
\omega_{0}=\frac{N}{R C} \sqrt{\alpha \beta} \\
Q=\frac{N}{N_{0}} \sqrt{\alpha \beta}
\end{gathered}
$$

The filter gains are

$$
\begin{gathered}
\mathrm{H}_{\mathrm{LP}}=\mathrm{H}_{\mathrm{HP}}=1 \text {, and the } \mathrm{H}_{\mathrm{BP}}=\mathrm{Q} \\
Q=N N_{0} \sqrt{\alpha \beta}
\end{gathered}
$$

It is evident from equation (13) and (14) that the non-idealities slightly affect the pole- $\omega_{0}$ and pole-Q. 


\section{DESIGN AND VERIFICATION}

All the realized digitally controlled current mode programmable analog modules of Section-1 were designed and verified by performing PSPICE simulation with supply voltage $\pm 0.75 \mathrm{~V}$ using CMOS TSMC $0.25 \mu \mathrm{m}$ technology parameters. The CMOS DPCCII with 4-bit current summing network at port-X (i.e. $m=-1$ ) of Fig. 1(b) was used for CMPAM-1 and CMPAM-2. The aspect ratios used are given in the Table 1. The CMPAM-3 was verified using the DPCCII with the CSN at port-Z (i.e. $m=1$ ). The CMPAM-1 i.e. the current amplifier was initially designed for a current gain of unity with $\mathrm{R}_{1}=\mathrm{R}_{2}=3.3 \mathrm{~K} \Omega$ and the then the gain was tuned through digital control word $\mathrm{N}$. The observed wave shapes at different $\mathrm{N}$ are shown in "Figure 6" at $100 \mathrm{KHz}$ frequency. The CMPAM-2 was initially designed for a cut frequency of $16 \mathrm{kHz}$ with $\mathrm{N}=1, \mathrm{R}=3.3 \mathrm{k} \Omega$ and $\mathrm{C}=3 \mathrm{nF}$. Then the pole frequency was controlled through digital control word $\mathrm{N}$. The observed frequency responses of the filter for different control words are given in "Figure 7".

Table 1: The aspect ratios of the MOSFETs of the DPCCII

\begin{tabular}{|c|c|c|}
\hline MOSFETs & $\mathbf{W} \boldsymbol{\mu m}$ & $\mathbf{L} \boldsymbol{\mu m}$ \\
\hline $\mathrm{M}_{1}, \mathrm{M}_{2,}, \mathrm{M}_{5}, \mathrm{M}_{6}$ & 5 & 0.25 \\
\hline $\mathrm{M}_{3,} \mathrm{M}_{4,}, \mathrm{M}_{7}, \mathrm{M}_{8}$ & 0.5 & 0.5 \\
\hline $\mathrm{M}_{9,} \mathrm{M}_{10}$ & 0.5 & 0.25 \\
\hline $\begin{array}{l}\mathrm{M}_{11}, \mathrm{M}_{12}, \mathrm{M}_{13}, \mathrm{M}_{14,} \\
\mathrm{M}_{15}, \mathrm{M}_{16,} \mathrm{M}_{17}, \mathrm{M}_{18}, \\
\mathrm{M}_{19}, \mathrm{M}_{23,}, \mathrm{M}_{27}, \mathrm{M}_{31}\end{array}$ & 25 & 0.25 \\
\hline $\mathrm{M}_{20}, \mathrm{M}_{24}, \mathrm{M}_{28}, \mathrm{M}_{32}$ & 50 & 0.25 \\
\hline $\mathrm{M}_{21}, \mathrm{M}_{25}, \mathrm{M}_{29}, \mathrm{M}_{33}$ & 100 & 0.25 \\
\hline $\mathrm{M}_{22,} \mathrm{M}_{26}, \mathrm{M}_{30}, \mathrm{M}_{34}$ & 200 & 0.25 \\
\hline
\end{tabular}

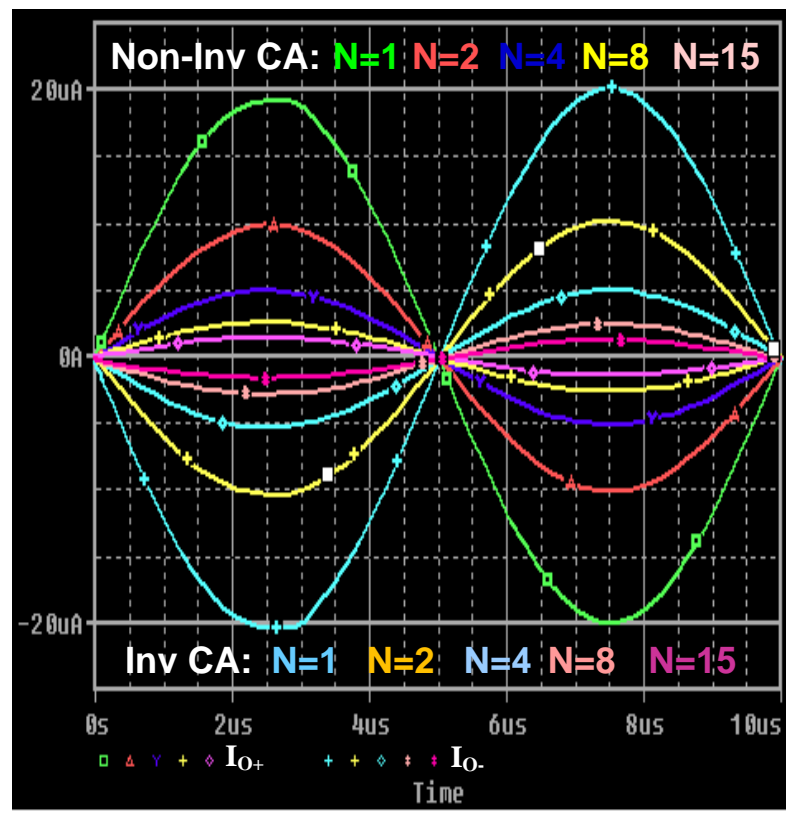

Fig 6: The output wave shapes at different control word $\mathbf{N}$ of the inverting and non-inverting current amplifier (CA) at $100 \mathrm{KHz}$.

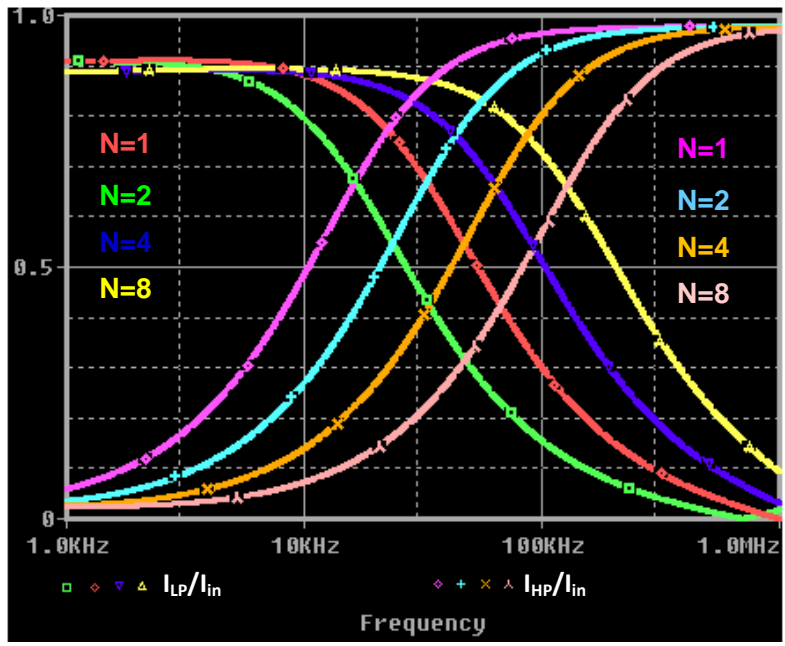

Fig 7(a): Frequency response of LP and HP first order current mode filters at different control word $\mathbf{N}$

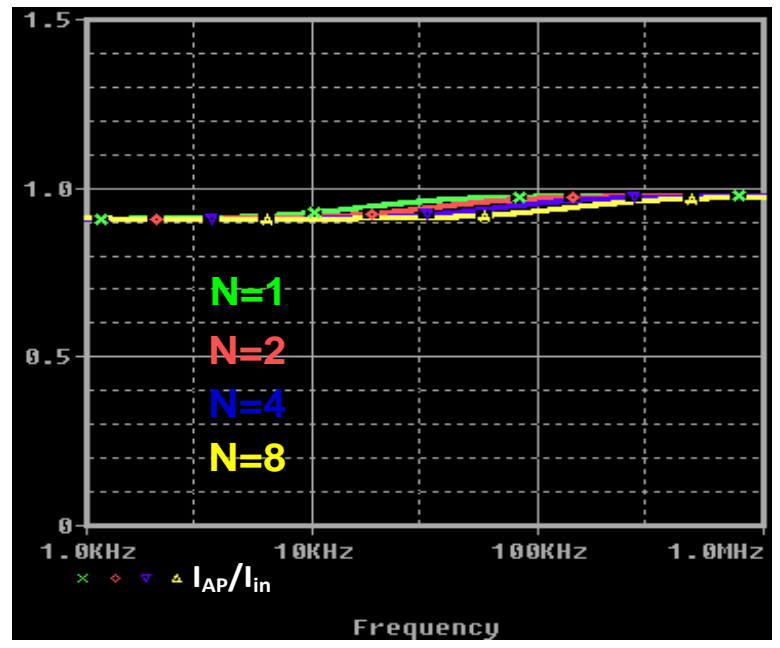

Fig 7(b): Frequency response of the first order current mode AP filter at different control word N

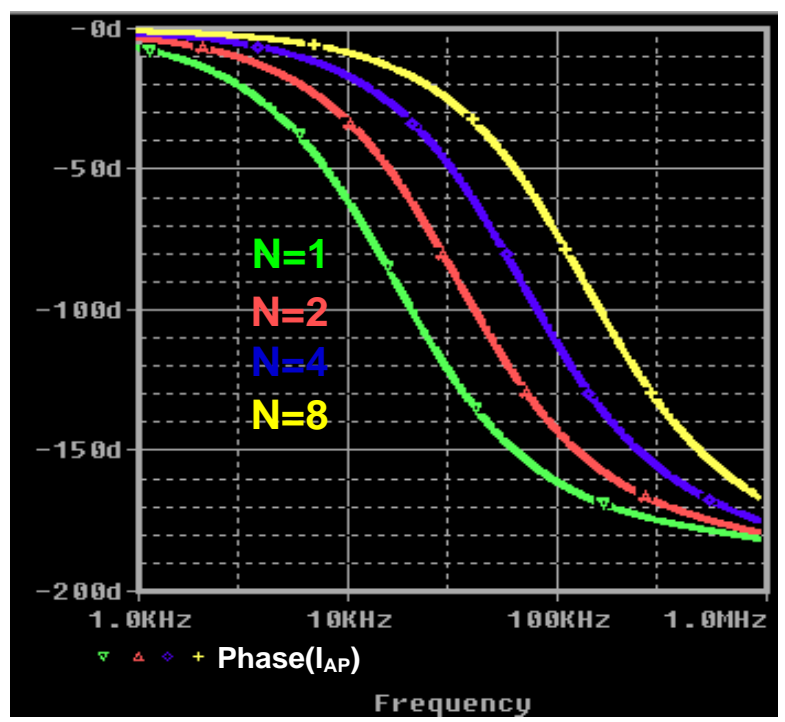

Fig 7(c): Variation of phase angle of the first order current mode AP filter at different control word $\mathbf{N}$ 


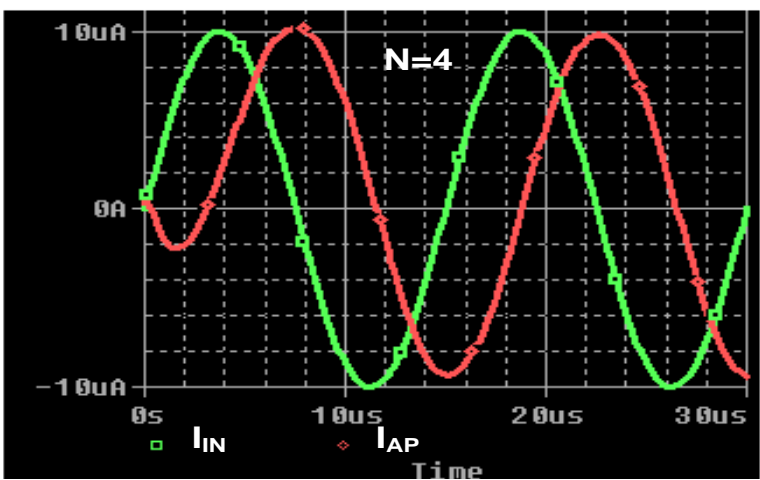

Fig 7(d): The input and output wave shapes of the first order all pass filter at $\phi=90^{\circ}$

The CMPAM-3 was initially designed for a pole frequency of $f_{0}=46.8 \mathrm{kHz}$ and pole- $\mathrm{Q}=1$ with $\mathrm{N}=\mathrm{N}_{0}=1, \mathrm{R}=13.6 \mathrm{k} \Omega$ and $\mathrm{C}=0.25 \mathrm{nF}$. Then the pole frequency was controlled through digital control word $\mathrm{N}$. The observed frequency responses of the filter for different control words are given in "Figure 8". All the results observed in "Figure 6" through "Figure 8" show the close conformity with the design.

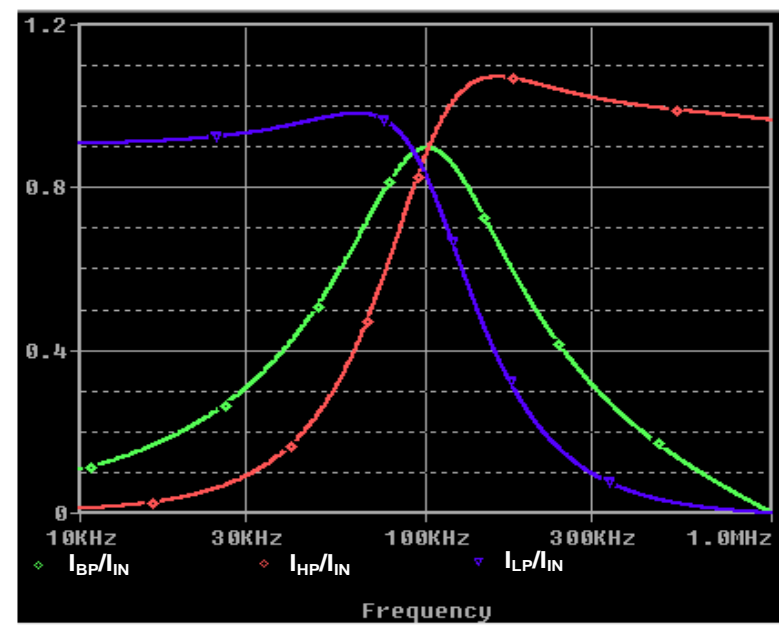

Fig 8(a): ): Frequency response of $\mathrm{LP}, \mathrm{HP}$ and $\mathrm{BP}$ second order current mode filter at control word $\mathrm{N}=2$

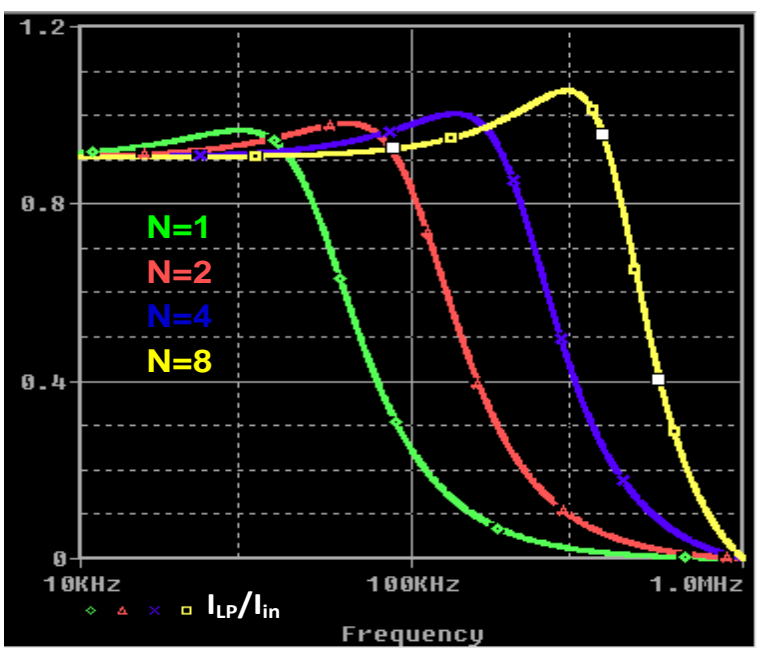

Fig 8(b): Frequency response of LP second order current mode filter at different control word $\mathrm{N}$

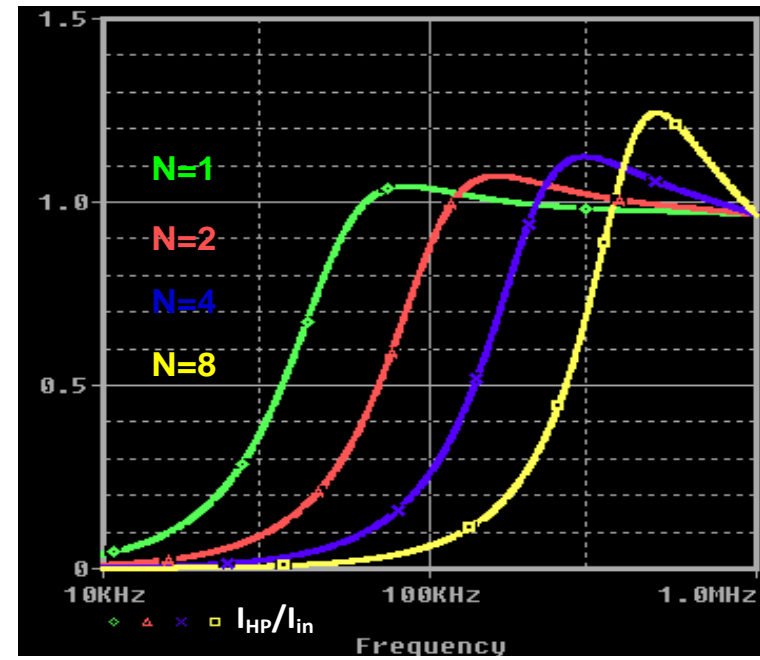

Fig 8(c): Frequency response of HP second order current mode filter at different control word $N$

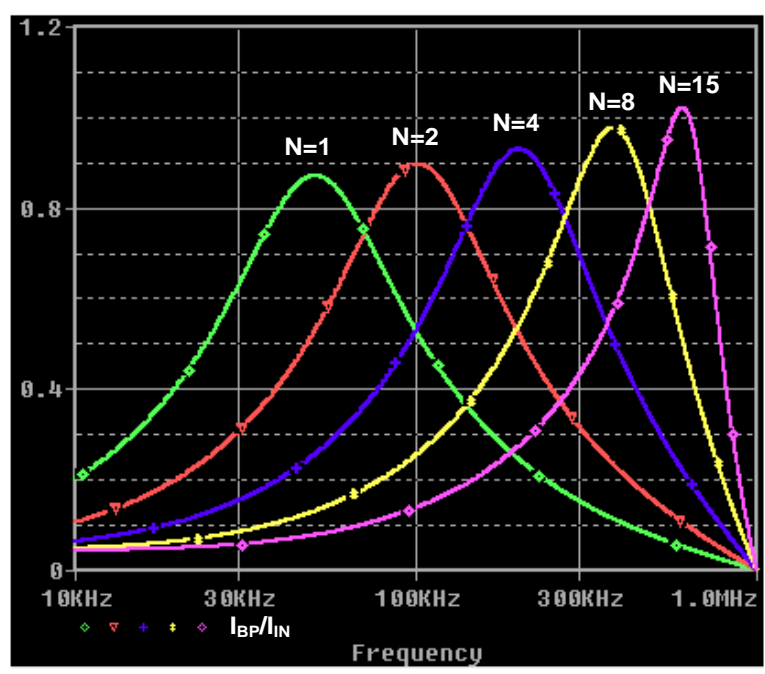

Fig 8(d): Frequency response of the BP second order current mode filter at different control word $\mathrm{N}$

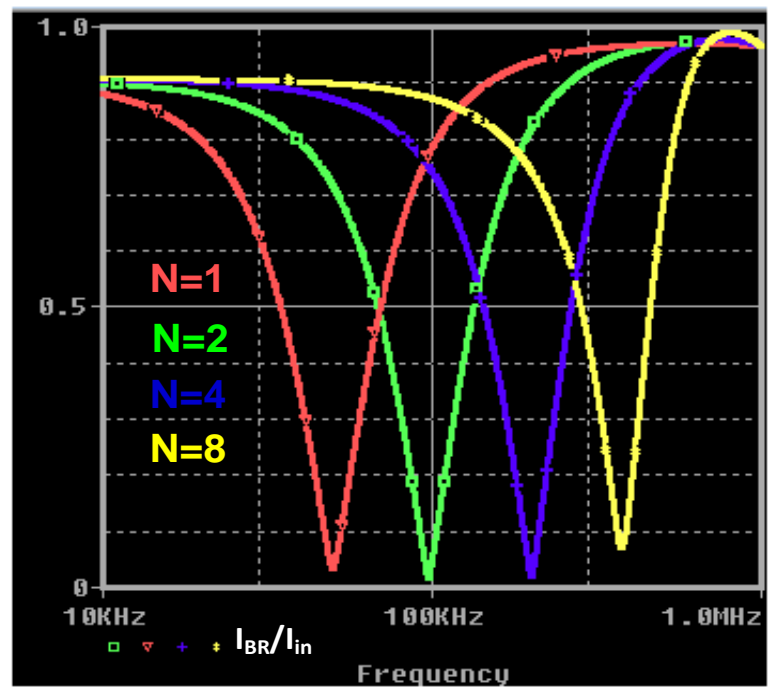

Fig 8(e): Frequency response of BR second order current mode filter at different control word $\mathbf{N}$ 


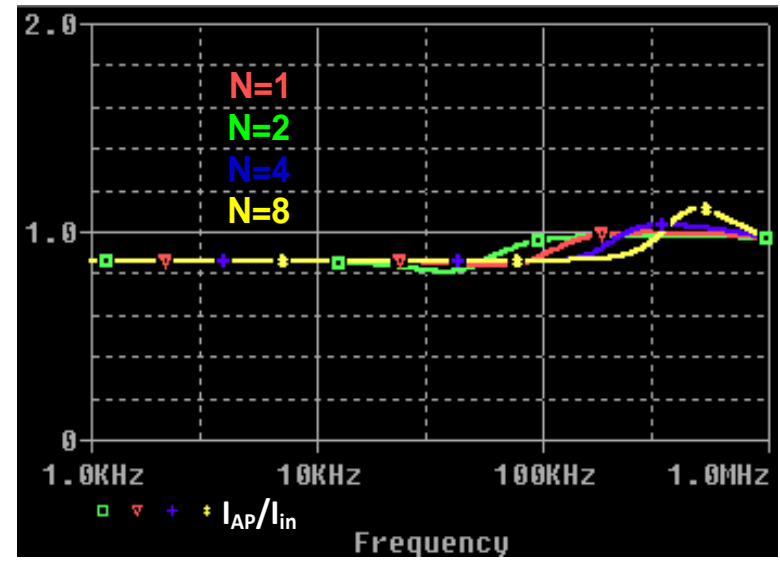

Fig 8(f): Frequency response of AP second order current mode filter at different control word $\mathrm{N}$

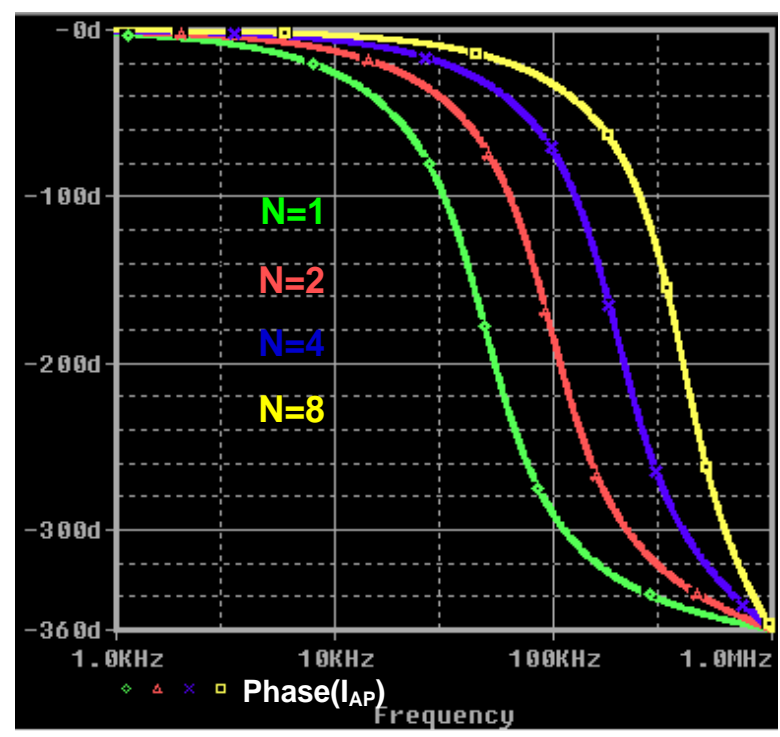

Fig 8(g): Variation of phase angle of the second order current mode AP filter at different control word $\mathbf{N}$

\section{CONCLUSION}

Three current mode programmable analog modules are realized using digitally controlled low voltage CMOS current conveyors. These programmable modules include current mode amplifiers with inverting and non-inverting outputs, integrators, differentiators, first order multifunctional filter wit low pass, high pass, and all pass filter sections. The third programmable analog module realized is second order current mode multifunctional filter which provides low pass, high pass, band pass, band reject and all pass responses. All the realized current mode programmable analog module parameters are digitally programmable through an n-bit control word with high resolution capability and reconfigurability. These programmable analog modules are suitable for realizing current mode field programmable analog array. All the three realized programmable analog modules were designed with minimal passive components' spread and verified using PSPICE. All the results thus obtained justify the theory.

\section{REFERENCES}

[1] Hassan, T. M. and Mahmoud, S. A. 2007, Low voltage digitally programmable band pass filter with independent control, IEEE International Conference on Signal Processing and Communications (ICSPC 2007), 24-27, Dubai, UAE.

[2] Khan, I. A., Khan, M. R. and Afzal, N. 2006, Digitally programmable multifunctional filters using CCIIs, Journal of Active and Passive Electronic Devices, 1, 213 220 .

[3] Khan, I. A., Khan, M. R. and Afzal, N. 2009, A Digitally Programmable Impedance Multiplier using CCIIs with High Resolution Capability, Journal of Active and Passive Electronic Devices, 8, 247-257.

[4] Hassan, T. M. and Mahmoud, S. A. 2009, Fully programmable universal filter with independent gain, $\omega_{0}$ and $Q$ control based on new digitally programmable CMOS CCII, Journal of Circuits, Systems and Computers, 18, No. 5, 875-897.

[5] Mahmoud, S. A., Hashiesh, M. A. and Soliman, A. M. 2005, Low-voltage digitally controlled fully differential current conveyor," IEEE Transactions on circuits and Systems-I, 52, No. 10, 2055-2064.

[6] Khan, I. A. and Simsim, M. T. 2011, A Novel Impedance Multiplier using Low voltage Digitally Controlled CCII, Proc. IEEE GCC Conference and Exhibition, Dubai, UAE, 331-334.

[7] Khan, I. A., Simsim, M. T. and Beg, P. 2011 , Reconfigurable Continuous Time Current Mode First Order Multifunctional Filter using Low voltage Digitally Controlled CMOS CCII, Proc. International Conference on Multimedia, Signal Processing and Communication Technologies (IMPACT-2011), 5-8, Aligarh, India

[8] Khan, I. A. and Nahhas, A. M. May, 2012, Reconfigurable Voltage Mode First Order Multifunctional Filter using Single Low voltage Digitally Controlled CMOS CCII, International J. Computer Applications(To Appear).

[9] Pal, K. and Rana, S. 2004, Some new first order all-apss realization using CCII, J. Active and Passive Elec. Comp., 27, 91-94.

[10] Khan, I. A. and Maheshwari, S. 2000, Simple first order all-pass section using a single CCII, International Journal of Electronics, 87, No. 3, 303-306.

[11] Mita, R., Palumbo, G. and Pennisi, S. 2003, 1.5-V CMOS CCII+ with High Current-Drive Capability, IEEE Trans. CAS-II, 50, No. 4, 187-190.

[12] Madian, A. H., Mahmoud, S. A. and Soliman, A. M. 2006, New 1.5V CMOS second generation current conveyor based on wide range transconductor, Analog Integrated Circuits and Signal Processing, 49, 267-279.

[13] Khan, I. A., Beg, P. and Ahmed, M. T. 2007, First Order Current Mode Filters and Multiphase Sinusoidal Oscillators Using MOCCIIs, Arabian Journal of Science and Engineering, Saudi Arabia, 32, No. 2C, 119-126.

[14] Beg, P., Khan, I. A. and Maheshwari, S. 2012, Biphase Amplifier based Precision Rectifiers using Current Conveyors, International J. Computer Applications, 42, No. 3, 14-18.

[15] Floyd, T. L. 2012, Electronic Devices Conventional Current Version, Ninth Edition, Pearson.

[16] http://www.anadigm.com-dynamically programmable Analog Signal Processor or Field Programmable Analog Array. 